\title{
EJNSO
}

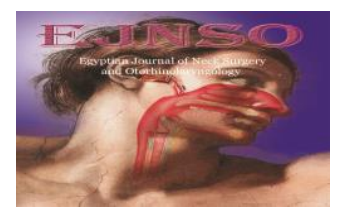

\section{Phoniatrics Protocol for assessment of stuttering used in Phoniatrics' unit Sohag University}

\author{
El-Adawy A. A.N., Emam A.M., Mostafa E. M. and Elbarody Z. M \\ Phoniatrics unit, Otorhinolaryngology, Faculty of Medicine- Sohag University.
}

\begin{abstract}
:
Objective: The aim of this study is to develop a protocol for assessment of stuttering in phoniatrics unit, Sohag University for better assessment and management of this problem.

Patients and Methods: The protocol included subjective and objective evaluation. This study was done on a group of 55 Arabic language children who stutter and their relatives attending to phoniatrics unit Sohag University Hospital complaining of stuttering.
\end{abstract}

Results: The validity of the test was examined by content validity by frequent revisions of the protocol by the expert phoniatricans of Sohag phoniatric unit (four phoniatricans) with experience about $5-25$ years. The reliability of the protocol was examined by a correlation between SSI and SW\%, speech rate and subjective evaluation and SW\% and speech rate.

Conclusion: The protocol of stuttering assessment in phoniatrics unit, Sohag University is suitable and easily applicable to assess stuttering and its severity. It will help in an accurate assessment of these patients and therefore putting a suitable plan for intervention.

Key words: Stuttering, stuttering severity, SSI-3, Protocol

\section{Introduction}

Stuttering has been recognized since antiquity and affects all populations ${ }^{1}$. Concerning findings, for several decades, an approximately 5\% lifespan incidence seems to have been the most frequently recognized and accepted statistic ${ }^{2}$.

It is a neurologically based speech disorder associated with cognitive linguistic, motor and emotional abnormalities that is characterized by involuntary repetitions, prolongations, blocks or hesitations of speech sounds 3. These are all overt speech events that carry acoustic and perceptual consequences that are available to the listener. However, some people who stutter are adept at obscuring the overt aspects of their disorder. They can speak without revealing to their speaking partner that they are a person who stutters, effectively passing as fluent speakers. Due to the secret nature of their stuttering, they are said to covertly stutter ${ }^{4}$.

The disorder typically arises in childhood, often as speech and language skills are rapidly developing. While the disorder resolves in the majority of individuals, either spontaneously or with the help of speech therapy, approximately 20-25\% of cases do not, leading to a condition known as persistent developmental stuttering, which affects approximately $1 \%$ of the general population ${ }^{5}$. 
There are many different protocols and guidelines for assessment of stuttering around the world like: ASHA (American Speech -Language Hearing Association) guideline for stuttering assessment ${ }^{6}$ and Royal College of Speech \& Language Therapists (RCSLT) guideline ${ }^{7}$. These guidelines are detailed, systematic and clear, but did not involve the recent tests for assessment or prediction of stuttering.

Also, the assessment protocol of fluency disorders of the Phoniatrics unit of Ain Shams University Hospitals, Cairo - Egypt ${ }^{8}$ and assessment of communication disorders in children protocols in California State University ${ }^{9}$.

Some of these protocols need to be more systematic, organized and more informative from the beginning with history talking, clinical examination to the needed clinical diagnostic aids including recent tests or instruments for prediction or assessment of the problem. Also, some protocols use screening tests which are time consuming.

The purpose of this study is to develop Sohag protocol for assessment of stuttering for better assessment and management of this problem.

\section{Patients and Methods:}

\section{Patients:}

This study was done on 55 Arabic language children who stutter and their relatives attending to phoniatrics unit complaining of stuttering.

The design of the protocol passed through these steps:

I.Reviewing of the available wellformed protocols and guidelines for assessment of stuttering like:

1. ASHA (American Speech Language -Hearing Association) guideline for stuttering assessment ${ }^{6}$.

2. Royal College of Speech \& Language Therapists (RCSLT) guideline ${ }^{7}$.

3. The assessment protocol of fluency disorders of the Phoniatrics unit of Ain Shams University Hospitals, Cairo Egypt $^{8}$.

4. Assessment of communication disorders in children protocols in California State University ${ }^{9}$.

These protocols were modified to be suitable with our culture and facility for application by phoniatrics' team at Sohag University Hospital.

II.The design of our protocol of assessment (see Appendix 1) was established by two phoniatrican after evaluation and discussion of available protocols of assessment, which included:

A. Preliminary diagnostic procedures which include:

1. History taking with special emphasis on age of family noticed, presence of delayed language or avoidance and previous therapy.

2.Examination: general, vocal tract and communicative assessment.

B. Clinical diagnostic aids: stuttering word $\%$ and speech rate.

C.Additional instrumental measures: SSI, Arabic Stuttering prediction Instrument and EEG.

\section{III.Evidence of validity of the test: \\ -Content validity:}

1. There were frequent revisions of the protocol by the expert phoniatricans of Sohag phoniatric unit (four phoniatricans) with experience about $5-25$ year.

2. Some items were added like :

- In the patient interview: the motivation of the patient and 
the family to the speech therapy.

- Subjective and objective evaluation.

- Using Arabic Stuttering prediction Instrument ${ }^{10}$ in early diagnosis of stuttering.

- EEG in the recommended investigation.

IV.Evidence of reliability of the protocol:

We correlate SSI with SW\% and speech rate, SW\% with speech rate and subjective evaluation with SSI.

\section{Statistical analysis:}

Data was analyzed using SPSS program version 17. Spearman's correlation was used for data which wasn't normally distributed (SSI and SW\%, SSI and speech rate SSI and subjective evaluation).

\section{Results:}

Our design for protocol of stuttering (Appendix 1):

\section{Subjective evaluation which done:}

1. At first interview.

2. After 2 months in follow up post family counselling.

3. Every 8 therapy sessions.

4. At the end of therapy sessions, then every 3 months for first year, then every 6 months (which should be followed up to 5 years).

II. Objective evaluation which include:

1. Arabic Stuttering prediction Instrument ${ }^{10}$ :

- Once stuttering suspected.

- If the patient was diagnosed as normal dysfluency: Every 3 months, 6 months and 1 year as follow up.

2. If the stuttering was diagnosed, Speech rate, stuttering word \% (SW\%) and Stuttering Severity
Instrument (SSI-3) $11 \quad$ were assessed:

- In the first interview.

- Every 16 session and at the end of the therapy then every 3,6 , 9, 12 month and 2 years as follow up.

3. EEG in the first interview.

This protocol was done on 55 Arabic language children who stutter.

There was positive correlation between SSI and SW\% and SSI and subjective evaluation. There was no correlation between SSI and speech rate (Table. 1, 2).

Table (1): Correlation between SSI and speech rate and stuttering word among the studied patients $(n=55)$.

$r=$ Spearman correlation coefficient

*Pearson Correlation

\begin{tabular}{|l|l||l|}
\hline \multirow{2}{*}{} & \multicolumn{2}{|l|}{ SSI } \\
\cline { 2 - 3 } & \multicolumn{1}{|l|}{$\mathbf{R}$} & P-value \\
\hline \hline Stuttering word\% & 0.742 & $<\mathbf{0 . 0 0 1}$ \\
\hline \hline Speech rate* & -0.187 & 0.171 \\
\hline
\end{tabular}

P-value $<0.05$ is statistically significant

Table (2): Correlation between SSI and subjective evaluation of the studied patients $(\mathrm{n}=100)$.

\begin{tabular}{||c||c|c|}
\hline \multirow{2}{*}{} & \multicolumn{2}{|l|}{ SSI } \\
\cline { 2 - 3 } & $\mathbf{R}$ & P-value \\
\hline Subjective evaluation & 9640. & $<\mathbf{0 . 0 0 1}$ \\
\hline
\end{tabular}

$\mathrm{r}=$ Spearman correlation coefficient

$\mathrm{P}$-value $<0.05$ is statistically significant

There was no correlation between SW\% and speech rate (Table. 3).

Table (3): Correlation between stuttering word and speech rate among the studied patients $(\mathrm{n}=$ 55).

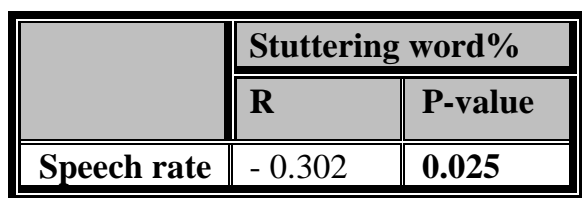

$\mathrm{r}=$ Spearman correlation coefficient

$\mathrm{P}$-value $<0.05$ is statistically significant 


\section{Discussion :}

In this study, a new protocol for evaluation of stuttering was designed to be more suitable for patients at our environment at Sohag governorate. The developed protocol revised by several phoniatricians with experiences ranging from 5 years up to 25 years.

Our protocol follows the commonly used guidelines with more details and more organization, also some tests which already were translated into Arabic were added to be more reliable and informative .

During history talking, age of onset of avoidance or escape was added. Also, family and patient motivation to speech therapy were added, which inform as about family beliefs and attitude toward stuttering and its therapy. Also, it will give idea about the prognosis.

Stuttering word (SW \%) was put in the clinical diagnostic aids, which give us impression about the stuttering severity and make the preliminary evaluation more reliable. Also, it was found that there is positive correlation between SSI and SW\%.

Using the Stuttering Severity Instrument (SSI-3) ${ }^{11}$ which is the most reliable test in assessment of stuttering severity. Also, using the Arabic Stuttering prediction Instrument ${ }^{10}$ for early discover of stuttering

Also, speech rate was added in the clinical diagnostic aids which may affect the stuttering severity. Among children who stutter, inconsistent results regarding their speech rates have been reported ${ }^{12}$. In this study, it was found that there is no correlation between SSI and speech rate. Meyers and Freeman (1985) reported that children with a severe stuttering disorder speak slower than their normally fluent peers ${ }^{13}$.

Also, Logan and Conture,1995 observed that some younger children who stutter (around three years of age) spoke at a rate one standard deviation below the mean for normally fluent children, which is inconsistent with our results ${ }^{14}$.

Others (Logan \&Conture, 1995) did not find significant differences between the speaking rates of children who stutter and those who do not, regardless of whether the utterances were produced fluently or were stuttered ${ }^{14}$.

The discrepancies among findings may be related to the methods used to calculate speech rate, and to the differences in stuttering severity between the groups of subjects in the studies ${ }^{12}$.

Applying the protocol of assessment of stuttering of Sohag phoniatric unit on the patients of Sohag University, allow us to be more aware about the nature, progress, severity of the disease which may affect our results of the management of this disorder.

\section{Conclusion:}

The protocol of stuttering assessment in phoniatrics unit, Sohag University is suitable and easy applicable to assess stuttering and its severity. It will help in accurate assessment of these patients and therefore putting suitable plan for intervention.

\section{Financial support and sponsorship:}

No financial support was obtained from any source.

\section{Conflicts of interest:}

The authors declared no potential conflicts of interest with respect to the research, authorship and/or publication of this article. 


\section{Reference:}

1. Bloodstein, O. and Ratner, N. (2008): A handbook on stuttering. (6th ed). Clifton Park, NY: Thomson Delmar Learning

2. Yairi, E., and Ambrose, N. (2013): Epidemiology of stuttering: 21st century advances. Journal of Fluency Disorders, 38, 66-87.

3. Yang, Y., Jia, F., Siok, W. T., \& Tan, L. H. (2017). The role of anxiety in stuttering: evidence from functional connectivity. Neuroscience, 346, 216225.

4. Moore, S. E., \& Perkins, W. H. (1990). Validity and reliability of judgments of authentic and simulated stuttering. Journal of Speech and Hearing Disorders, 55(3), 383-391.

5. Frigerio-Domingues, C., \& Drayna, D. (2017). Genetic contributions to stuttering: the current evidence. Molecular genetics \& genomic medicine, 5(2), 95-102

6. American Speech-Language-Hearing Association. (1995). Guidelines for practice in stuttering treatment

7. Royal College of Speech \& Language Therapists. (2005). RCSLT-Royal College of Speech \& Language Therapists Clinical Guidelines. Speech mark.

8. Kotby, M., Youssef, M. and Refaie, N., (2015): Fluency disorders, Disorders of Speech and Swallowing for Phoniatrics and Communication Disorders. A Publication of the Egyptian Society of Phoniatrics and Logopedics, El Hariry print, Cairo, Egypt

9. Hegde, M. N., \&Pomaville, F. (2016). Assessment of communication disorders in children: Resources and protocols (3rd Ed). Plural Publishing. California State University, Fresno.

10.Mohamed, R., Rifaie, N., El Dory, G., Ghandour, H., and Nassar, J., (2015): Arabic Stuttering prediction Instrument"- (Unpublished doctoral thesis .(Ain Shams University, Cairo, Egypt.

11.Riley GD (1994). Stuttering severity instrument for children and adult, third edition. Pro-ed. Austin Texas.
12.Savelkoul, E. M. (2001). Coordinated interpersonal timing in children who stutter (Unpublished doctoral dissertation). The University of Iowa, Iowa, United States .

13.Meyers. S. C., \& Freeman, F. J. (1985). Interruptions as a variable in stuttering and disfluency. Journal of Speech and Hearing Research, 28,428-435

14.Logan, K. J., \&Conture, E. G. (1995). Length, grammatical complexity, and rate differences in stuttered and fluent conversational utterances of children who stutter. Journal of Fluency Disorders, 20(1), 35-61. 


\section{Appendix 1 \\ Case Sheet for Stuttering}

\begin{tabular}{llc} 
Name & Date & Tell. No \\
Address & Birth date & \\
Order of Birth & Age & \\
Consanguinity & Similar condition in the family \\
Father Job & Mother Job & Education \\
Occupation & & \\
Marital Status & Handedness & Right or Left-Handed Foot \\
\hline Diagnosis: & & \\
\hline
\end{tabular}

A) Preliminary Diagnostic Procedures:

i. Complaint:

Duration Onset Course

ii. History:

- Prenatal, Perinatal, Postnatal History:

-Developmental History:

$\begin{array}{lll}\text { Waking } & \text { Teething } & \text { Toilet Training } \\ \text { Self-feeding } & \text { Self dressing } & \\ \text { First word } & \text { First sentence } & \end{array}$

- History of present illness:

- The cause is suggested by family

- The etiology for seeking help

- Age of onset of family notice

Age of onset of patient awareness

Age of onset of patient suffering from it

Age of onset of escaping and avoidance

- Patient subjective evaluation

- Effect of stuttering on patient:

Socially Academically

- Family subjective evaluation

Economically

- Presence of difficulty in specific phoneme, word, situation and.... etc.

- The condition which increase stuttering severity

- The condition which decrease stuttering severity

- Fear, escape, and avoidance of speech situation

- How to manage this situation

- Previous therapy

Medication

Speech therapy: Place: Number: Duration: Result:

- Subjective impression of:

Hearing Mentality Social interaction

- History of Fits, Head trauma, General diseases and......etc.

- Previous investigation: EEG, Audio, CT.

- Scholastic achievement

- Motivation of patient about stuttering and its therapy

Motivation of family about stuttering and its therapy 
iii. Examination:

- General look

- Local Examination

- Ear

- Nose

- Vocal tract

- Communicative Evaluation

* Language assessment

- Passive Vocabulary

- Active Vocabulary

Visual Perceptual Assessment

- Eye contact: Poor - Fair - Good

- Associated movements: Head nodding, Jaw movement, Eye blinking, Extremities Movement $\quad 0 \begin{array}{lllll}1 & 2 & 3 & 4\end{array}$

* Auditory Perceptual Assessment

- Automatic Speech

- Reading

$\begin{array}{lllll}0 & 1 & 2 & 3 & 4\end{array}$

- Spontaneous Speech

Repetition

$\begin{array}{lllll}0 & 1 & 2 & 3 & 4\end{array}$

Prolongation

01234

Blocks

01234

Interjected speech

01234

Silent pause

circumlocution Shwa vowel

Duration

-Distracting sounds: noisy breathing, whistling, sniffing, $\begin{array}{llllll}\text { blowing, clicking sounds) } & 0 & 1 & 2 & 3 & 4\end{array}$

- Speech Rate: $\quad$ Normal - Increased - Decreased

B) Clinical Diagnostic Aids:

$\begin{array}{llllll}\text {-Speech intelligibility } & 0 & 1 & 2 & 3 & 4\end{array}$

-Stuttering Word \%:

$----\cdots----\cdots$

- - - - - - - - - - - - - -

$---------------$

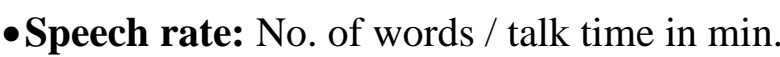

C) Additional Instrumental Measures:

-Stuttering syllable \%:

-Stuttering severity index:

- EEG: 